\title{
Analysis and design of hollow wpc sheet piling in marine projects
}

\begin{abstract}
Traditional waterfront construction materials often have a multitude of problems due to the harsh environmental conditions. On the shoreline, retaining walls are commonly used to prevent shoreline erosion and maintain the earth's stability. Traditional materials used are steel, reinforced concrete, and timber. Steel and reinforced concrete will deteriorate due to corrosion and spelling. Timber requires chemical treatment and can be attacked by marine borers. To respond to these major issues, several alternative materials have emerged for marine waterfront construction applications, these materials include plastic and composite materials. One viable option for retaining wall material is WPC. WPCs are a mixture of a thermoplastic resin and wood fibers. To date WPC has been used successfully in many applications including decking, railings, and fencing. The two main advantages of WPC are the material properties (e.g. durability, lightweight, recyclable) and its ability to be produced in a wide range of geometric configurations. These advantages can be utilized by applying the material to more innovative applications such as retaining walls in marine structures.
\end{abstract}

The Sharm El-sheikh port the case study, its construction date 1963, land area equal $0,162 \mathrm{~km}^{2}$, channel length equal $40 \mathrm{~m}$ depth, number of quays equal $1,625 \mathrm{~m}$ Long, between 5 to $8 \mathrm{~m}$ depth, number of scaffold equal 2 of $180 \mathrm{~m}$ long, and the capacity: 100,000 passenger/tourist. The overall objectives of this research can be divided into two categories: First making a finite element model for the Sharm El-shikh Berth and comparing the results of WPC and Steel Sheet pile wall, and the second comparing the cost of WPC and Steel Sheet pile walls.
Volume I Issue 2 - 2016

\author{
Ayman Zakaria \\ Department $f$ Civil Engineering, University of Ain Sham, Egypt
}

Correspondence: Ayman Zakaria, Department of Civil Engineering, University of Ain Sham, Egypt, Tel +2 01001010552 , Emaildr_aymanz@yahoo.com

Received: October 24, 2016 | Published: November 23, 2016

\section{Introduction}

Traditional waterfront construction materials often have a multitude of problems due to the harsh environmental conditions. On the shoreline, retaining walls are commonly used to prevent shoreline erosion and maintain the earth's stability. Traditional materials used are steel, reinforced concrete, and timber. Steel and reinforced concrete will deteriorate due to corrosion and spalling. Timber requires chemical treatment and can be attacked by marine borers. To respond to these major issues, several alternative materials have emerged for marine waterfront construction applications, these materials include plastic and composite materials. One viable option for retaining wall material is WPC. WPCs are a mixture of a thermoplastic resin and wood fibers. To date WPC has been used successfully in many applications including decking, railings, and fencing. The two main advantages of WPC are the material properties (e.g. durability, lightweight, recyclable) and its ability to be produced in a wide range of geometric configurations. These advantages can be utilized by applying the material to more innovative applications such as retaining walls in marine structures. ${ }^{1-3}$

The Sharm El-sheikh port the case study a shown in Figure 1, its construction date 1963 , land area equal $0,162 \mathrm{~km}^{2}$, channel length equal $40 \mathrm{~m}$ depth, number of quays equal $1,625 \mathrm{~m}$ Long, between 5 to $8 \mathrm{~m}$ depth, number of scaffold equal 2 of $180 \mathrm{~m}$ long, and the capacity: 100,000 passenger / tourist.

The overall objectives of this research can be divided into two categories: First making a finite element model for the Sharm El-shikh Berth according to Figures 1-3 and comparing the results of WPC and Steel Sheet pile wall, and the second comparing the cost of WPC, PVC and Steel Sheet pile.

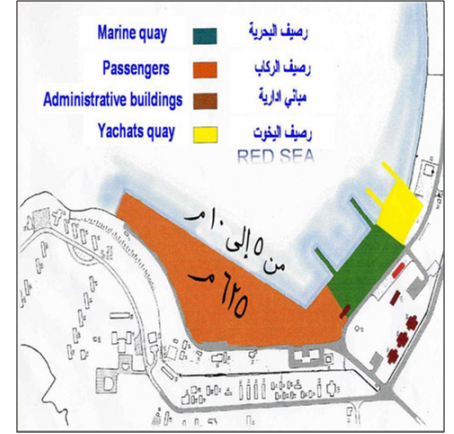

Figure I Sharm El-sheikh master plan.

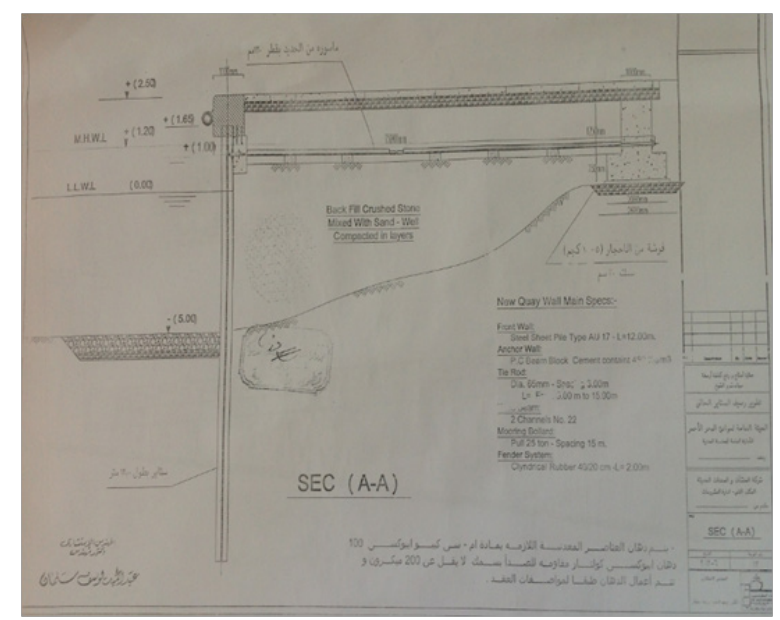

Figure 2 Sharm El-sheikh new berth x-section. 


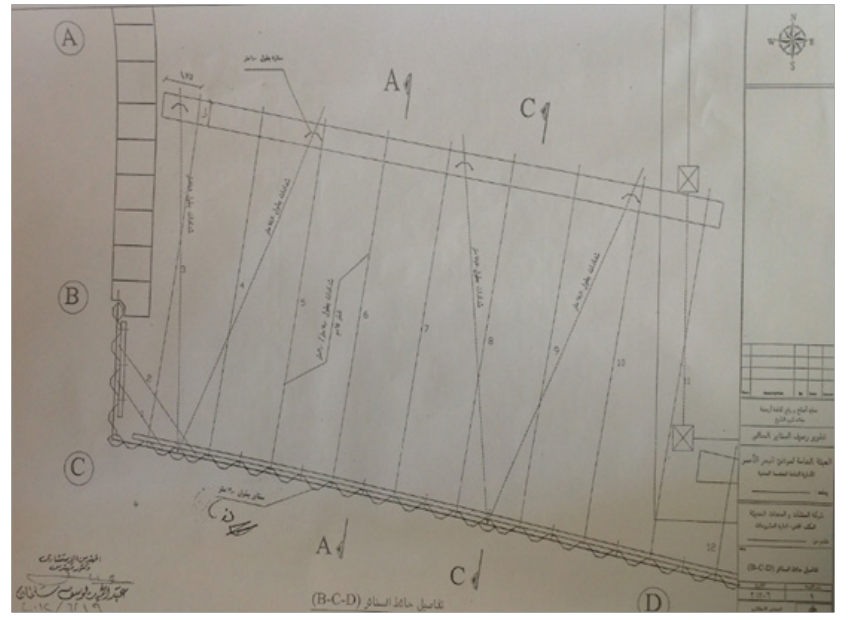

Figure 3 Sharm El-sheikh new berth plan.

\section{WPC background}

Wood plastic composites (WPC) consist of wood filler within a thermo plastic polymer. This wood filler can typically represent up to $50-60 \%$ of the total section weight, thereby reducing the cost of the thermoplastic polymer. The inclusion of wood flour will alter the mechanical properties of the final section, thus modifying the performance. There are also minor additives included in wood plastic composites consisting of colorant, lubricant, and UV inhibitors. Polypropylene (PP) is a typical thermoplastic polymer used for manufacturing WPC materials. There are several variations for polypropylene production. Samples of the raw wood flour and polypropylene pellets are shown in Figure 4A \& 4B.

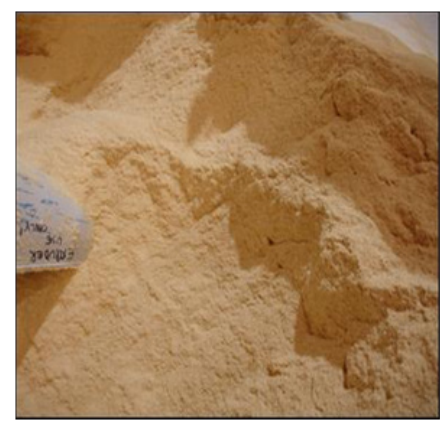

a. Wood Flour

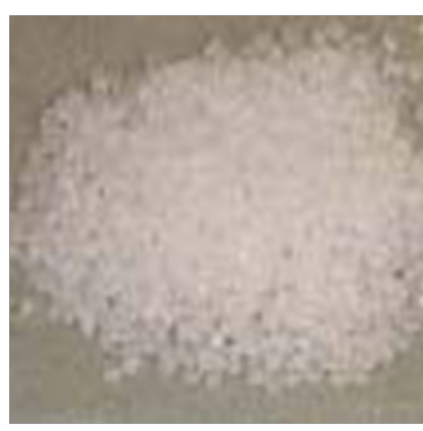

b. Raw Polypropylene
Figure 4 Wood plastic composite raw materials.

The basic material properties for WPC (composed of PP and $40 \%$ wood floor by weight) are compared to pure PP properties and rigid PVC properties in Table 1. WPC consists of a combination of American Wood Fiber 3020 (40 mesh pine fiber), Accpro ${ }^{\circledR} 9346$ Enhanced PP Resin, TPW 113 (commercial lubricant package), Clariant (polyethylene based colorant combined with an ultraviolet light stabilizer), and Polybond 3200 coupling agent, as shown in Table 1 .

\section{Material cost efficiencies}

Wood plastic composites provide the advantage of wood filler within a thermoplastic polymer, possibly reducing cost compared to all-plastic sections. Wood flour can typically represent up to $60 \%$ of the total section weight. This reduces the 33-weight requirement for the more expensive thermoplastic polymer. Equation (1) is an equation used to estimate the cost of different blends of polypropylene and wood flour blends and Table 2 uses this equation to determine the cost efficiency for various wood plastic composite blends. ${ }^{4-6}$

$$
\$ / l b=[P(X)+F(Y)+C] / E
$$

Where $\$ / \mathrm{lb}$ is the product cost in dollars per pound, $\mathrm{P}$ is the percent of plastic in composite, $\mathrm{X}$ is the estimated cost of the plastic in cents per pound, $\mathrm{F}$ is the percent of wood fiber in the composite, $\mathrm{Y}$ is the estimated cost of the fiber filler in cents per pound, $\mathrm{C}$ is the cost of compounding in cents per pound, $\mathrm{E}$ is the efficiency of operation. Table 2 highlights the benefit of adding wood fiber filler to a plastic matrix. As shown the mixture with the highest percentage of wood filler $(60 \%)$ has a cost savings of $\$ 21(29 \%)$ over the mixture with a lower wood filler percentage of $30 \%$. The addition of wood filler also alters the mechanical properties of a pure plastic, therefore a proper comparison of WPC to an all-vinyl section must take this change of mechanical properties into consideration. The primary differences between mechanical properties are evident in the modulus of elasticity, modulus of rupture, tensile strength, compressive strength, and flexural strength as shown in Table 3.

Table I Mechanical properties of rigid PVC and WPC

\begin{tabular}{lll}
\hline Properties & Rigid PVC & WPC ** \\
\hline $\begin{array}{l}\text { Flexural Strength (psi [MPa]) } \\
\text { ASTM D 790 }\end{array}$ & $12,500[86.2]$ & $6,410[44.2]$ \\
$\begin{array}{l}\text { Tensile Modulus (psi [MPa]) ASTM } \\
\text { D 638 }\end{array}$ & $475,000[3275]$ & $561,000[3867]$ \\
$\begin{array}{l}\text { Flexural Modulus (psi [MPa]) } \\
\text { ASTM D 790 }\end{array}$ & $300,000[2068]$ & $439,000[3026]$ \\
$\begin{array}{l}\text { Izod impact (ft-lb/in. of notch } \\
\text { J/m]) ASTM D 256 }\end{array}$ & $0.4[20]$ & $0.42[22.2]$ \\
$\begin{array}{l}\text { Heat deflection Temperature }\left({ }^{\circ} \mathrm{F}\right. \\
\left.\left[{ }^{\circ} \mathrm{C}\right]\right) \text { ASTM D 648 }\end{array}$ & $155[68]$ & $192[89]$ \\
Density (lb/ft3 [g/cm $\left.\left.{ }^{3}\right]\right)$ & $74.3[1.19]$ & $65.5[1.05]$ \\
\hline
\end{tabular}

Table 2 Cost comparison for various WPC mixtures

\begin{tabular}{lllllll}
\hline $\mathbf{P}$ & $\mathbf{X}$ & $\mathbf{F}(\%)$ & $\mathbf{Y}$ & $\mathbf{C}$ & $\mathbf{E}$ & $\$ / \mathbf{l b}$ \\
\hline $70 \%$ & 0.8 & 30 & 0.08 & 0.2 & $\mathrm{I}$ & 0.784 \\
$60 \%$ & 0.8 & 40 & 0.08 & 0.2 & $\mathrm{I}$ & 0.712 \\
$50 \%$ & 0.8 & 50 & 0.08 & 0.2 & $\mathrm{I}$ & 0.64 \\
$40 \%$ & 0.8 & 60 & 0.08 & 0.2 & $\mathrm{I}$ & 0.568
\end{tabular}

Table 3 PP-WPC and PVC cost and material properties comparison

\begin{tabular}{lll}
\hline & $\begin{array}{l}\text { PP-WPC (50\% } \\
\text { wood flour) }\end{array}$ & $\begin{array}{l}\text { Pure } \\
\text { PVC }\end{array}$ \\
\hline Unit material Cost & 0.45 & 0.7 \\
Ultimate Flexural Strenth (psi) & 6,000 & 12,000 \\
Unit Cost / Bending Strength( $(\$ * i n 2$ & $7.5 \times 10^{-5}$ & $\begin{array}{l}18.55 \times 10^{-} \\
\text {//lb2 ) }\end{array}$ \\
$\begin{array}{ll}\text { Bending Modulus, MOE (psi) } \\
\text { Unit Cost / Bending Modulus(\$/ft3/psi) }\end{array}$ & $1.95 \times 10^{-6}$ & $1.75 \times 10^{-6}$ \\
\hline
\end{tabular}




\section{Guided design tables}

These tables incorporate both long term and short term deflections. Short term deflection has allowable deflection limits of $\mathrm{L} / 40$ and $\mathrm{L} / 60$; and long term deflection has the same limits with an additional safety factor of 3. Table 4 is an example of a design table for a $200 \mathrm{psf}$ (9576 $\mathrm{Pa}$ ) surcharge. The design tables show the range of allowable wall heights achievable with the proposed WPC sections. The wall height is the length of the wall from the top of the pile to the embedment location. The design tables may be used to draw two main conclusions:

I. Maximum allowable wall height is largely based on suitable backfill. The backfill selection should be based on the characteristics and drainage properties of the soil. The correct soil choice varies for each situation and the correct soil will prevent considerable water lag behind the wall.

II. The maximum wall height can be controlled by either mean ultimate bending strength or short term deflection. As the surcharge load increases, deflection is more likely to limit the wall height, and mean ultimate bending strength is less likely to control.

Table 4 Design Table for a 200 psf (9576 pa) surcharge:Allowable Wall Height (ft. [m])

\begin{tabular}{|c|c|c|c|c|}
\hline Deflection & $\mathbf{L} / 40$ & & $L / 60$ & \\
\hline Walers & I & 2 & 1 & 2 \\
\hline \multicolumn{5}{|c|}{8 Inch Section* (Web and Flange Hollows) } \\
\hline Loose Fine Sand & II.5 [3.5] & $17[5.2]$ & $\mathrm{II} .5[3.5]$ & $17[5.2]$ \\
\hline Dense Fine Sand & I3.2[4.0] & $18[5.5]$ & I3.2 [4.0] & $18[5.5]$ \\
\hline Loose Gravel & II.5 [3.5] & $16.7[5.1]$ & $\mathrm{II} .5[3.5]$ & $16.7[5.1]$ \\
\hline \multicolumn{5}{|c|}{10 Inch Section* (Web and Flange Hollows) } \\
\hline Loose Fine Sand & $13.5[4.1]$ & I9.3 [5.9] & $10.5[3.2]$ & $17.5[5.3]$ \\
\hline Dense Fine Sand & I4.2 [4.3] & $22.5[6.9]$ & $13.5[4.1]$ & $22.5[6.9]$ \\
\hline Loose Gravel & I5.6 [4.8] & $22.5[6.9]$ & I3.7 [4.2] & $22.3[6.8]$ \\
\hline \multicolumn{5}{|c|}{ II.75 Inch Section* (Web and Flange Hollows) } \\
\hline Loose Fine Sand & $15[4.6]$ & $20[6.1]$ & $15[4.6]$ & $20[6.1]$ \\
\hline Dense Fine Sand & $17[5.2]$ & 22 [6.7] & $17[5.2]$ & 22 [6.7] \\
\hline Loose Gravel & $17[5.2]$ & $23.5[7.2]$ & $17[5.2]$ & $23.5[7.2]$ \\
\hline
\end{tabular}

\section{Analysis using linear finite element modeling}

The objective of the finite element model is to predict the response of two cases for this research, the first is AU17 steel sheet pile wall as shown in Figure 5, and the second is the response of a WPC 11.75 inch $29.85 \mathrm{~cm}$ deep sheet pile with hollows in the web and the flange wall section to various pressures representing design loadings. To analyze the above two cases the following steps should be taken:

\section{Material properties}

The material properties of the Hot rolled steel sheet piles used AU17, of grade S 240GP with a modulus of elasticity (E) 2.1E5MPA, a Poisson's ratio ( $v$ ) of 0.33 , min tensile strength (340MPA), min yield strength 240MPA and Min elongation at failure $26 \%$. The material properties of polypropylene wood plastic composites vary with the specific formulation used. In this FEA model, the WPC is modeled as a material with a 51 modulus of elasticity (E) of (3000 MPa) and a Poisson's ratio $(v)$ of 0.33 . These values were obtained from laboratory testing performed at the University of Maine. ${ }^{5}$ The average ultimate tensile and compressive strength are assumed to be $17.2 \mathrm{MPa}$ and 43.5MPa respectively, based on material testing also performed at the University of Maine Dura 2005.

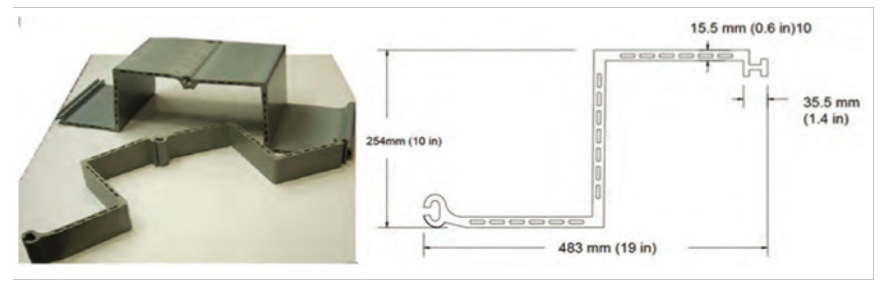

Figure 5 WPC sheet pile system for seawall applications.

\section{The applied loads}

The loads on the wall are the active and passive soil pressures, surcharge load, water pressure and the incident waves. The loads are shown schematically in Figures $6 \& 7$. To obtain a resultant pressure distribution, WALLAP sheet piling design software was used. This program uses the surcharge, soil, and hydrostatic loads to compute a comprehensive pressure distribution on the wall. Figure 7 show the pressure distribution for this model, which allows for full movement of the wall and including tieback forces. This model is for a $12 \mathrm{~m}$ wall, with a $7 \mathrm{~m}$ exposed length between the top and embedment. A waler is located $1.5 \mathrm{~m}$ from the top of the wall, and there are two water level locations low water levels and high water levels. The working case which includes the reflection of waves can cause waves to impact with each other that can lead to the increase in wave height forming a phenomenon called standing waves or a clapotis. Standing waves can be regarded as the superposition of two progressive waves, which move in opposite directions; Figure 8.

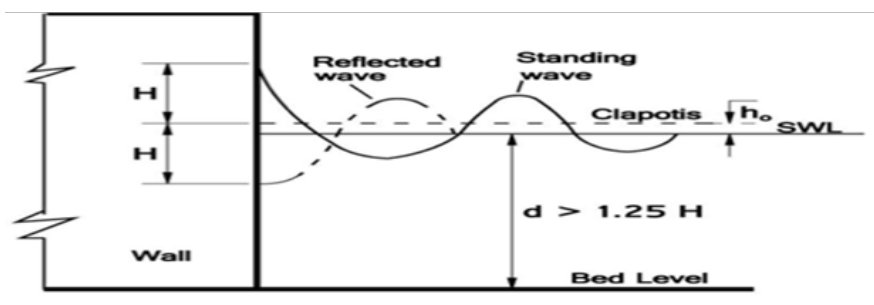

Figure 6 Incident waves and wave reflection.

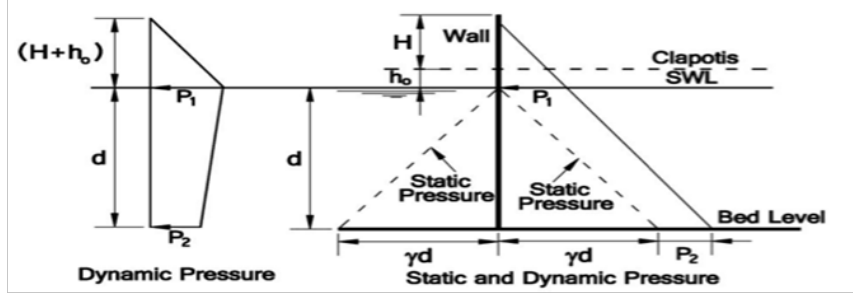

Figure 7 Sainflou's method for pressure distribution (At wave impact).

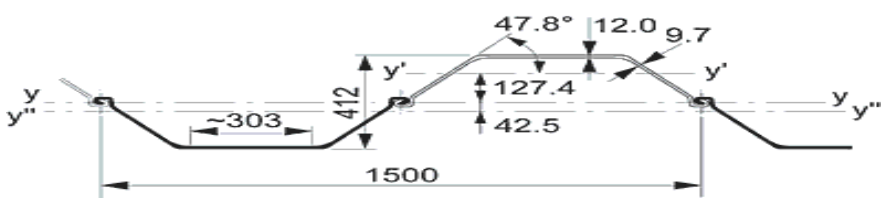

Figure 8 AUI7 used in sheet pile wall. 


\section{Design methodology}

The WALLAP software analyses a wide range of retaining wall problems including cantilevered walls, anchored walls and strutted excavations. WALLAP offers two separate types of analysis within the program:

a. Limit Equilibrium Analysis: Calculation of Factors of Safety according to one of the following methods: CP2, BSC Piling Handbook, Burland-Potts, and Strength factor method.

b. Bending moment and Displacement Analysis: Modeling of the stage by stage development of forces and wall movements as construction proceeds.

The wall and soil are modeled as a beam and springs. Two spring models are available: Sub grade reaction analysis for routine design, 2-D Finite element analysis for a more rigorous approach. The analysis includes the following features: Elastic soil behavior, Active and Passive limits, Effect of construction sequence, Strut pre-stressing, Finite length of the wall, Simple non-linear elastic soil model (optional), Soil below the wall 2-D FE analysis only, Soil arching 2-D FE analysis only. The analysis produces an economical design, which automatically takes account of any moment reduction due to fixed earth support.

\section{Steel sheet pile wall model results}

The overall maximum deflection predicted by WALLAP for AU17 section $3.7 \mathrm{~cm}$ in the y direction occurring at a position $5.40 \mathrm{~m}$ from the origin as shown in Figure 9. And this value is allowed as the max deflection from the steel beams codes is $\mathrm{H} / 200$ equal $3.75 \mathrm{~cm}$. The shearing forces and bending moment's predictions from the FEA model are presented in Figure 10. The maximum +ve bending moments are $103 \mathrm{KN} . \mathrm{m} / \mathrm{m}$ located at level $0.50 \mathrm{~m}$, and the maximum -ve bending moments $-205 \mathrm{Kn} . \mathrm{m} / \mathrm{m}$ located at level $(6.00 \mathrm{~m})$. the maximum + ve shearing force is $104 \mathrm{KN} / \mathrm{m}$ located at level $1.00 \mathrm{~m}$, and the maximum -ve shearing force is $-108 \mathrm{KN} / \mathrm{m}$ located at level $10.00 \mathrm{~m}$, the max tie rod force is $377 \mathrm{KN}$. The max straining actions above is satisfying the stresses for the cross section used AU17 in the Sharm berth.
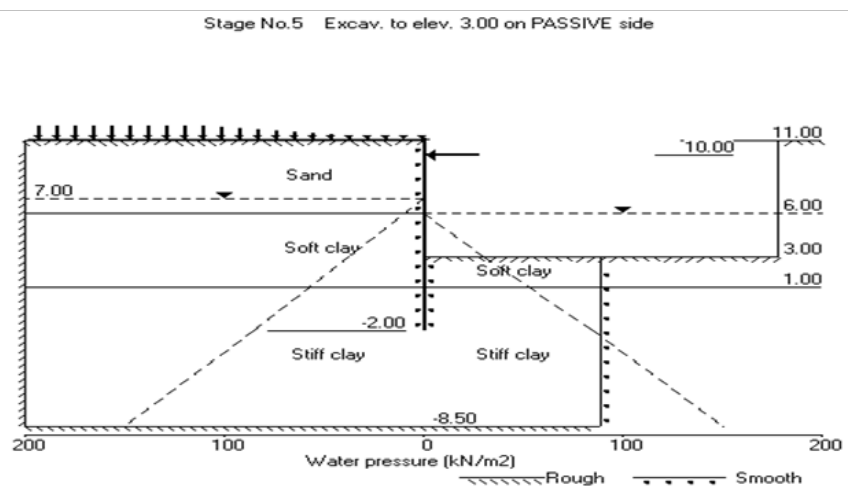

Figure 9 FEA model for AUI7 steel sheet piles.

\section{WPC wall model results}

a. In this model we used three anchors after many trials to satisfy the allowable deformations as shown in Figure $11 \& 12$

b. A factor of safety of four was used for calculating the allowable bending strength from the mean ultimate bending strength
This is to account for creep and additional serviceability issues. This number was based on current data available on the creep behavior of WPC members.

c. The deflection limits used are unsupported height/40 and unsupported height $/ 60$. These limits are based on the standard design utilized currently for PVC ribbed sheet piles. The length used for these calculations is the maximum unsupported height of the wall. For two walers the height is the distance between the walers. For one waler the height is between the embedment location and the waler.

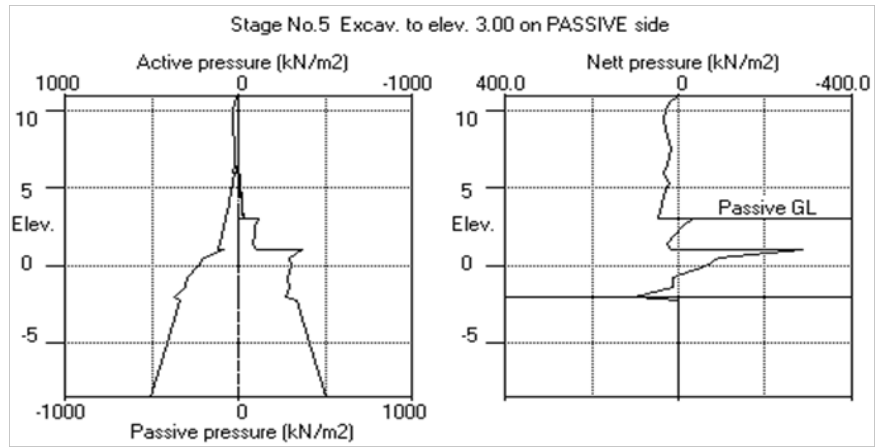

Figure 10 Active, passive and net pressure for AUI7 steel sheet piles.

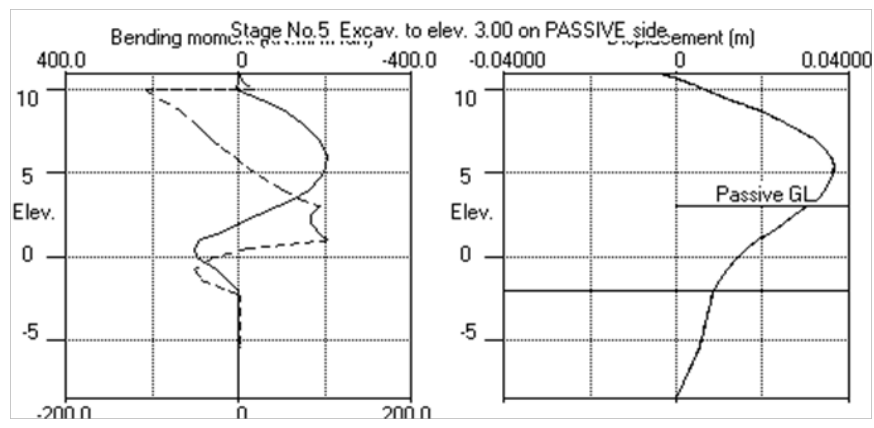

Figure I I Total deflection, shearing forces and bending moments for AUI7 steel sheet piles.

Stage No.8 Excav. to elev. 3.00 on PASSIVE side

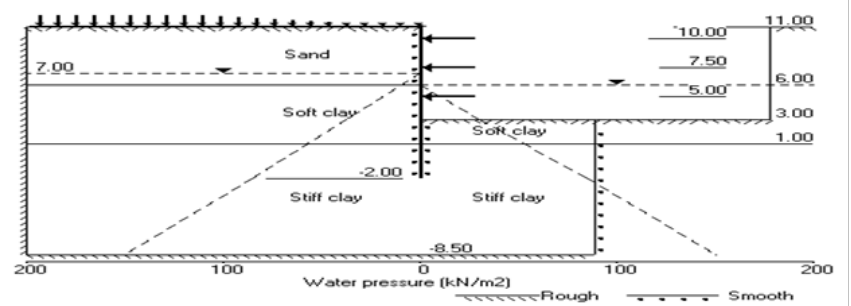

Figure I 2 FEA model for WPC (I I.75 Z section).

\section{Deflection, Shearing forces and Bending Moments}

The overall maximum deflection predicted by WALLAP for WPC $11.75 \mathrm{Z}$ section is $6.7 \mathrm{~cm}$ in the $\mathrm{y}$ direction occurring at a position $(7.00 \mathrm{~m})$ from the origin as shown in Figure 13. And this value is allowed as the max allowable deflection is about $7 \mathrm{~cm}$. The shearing forces and bending moment's predictions from the FEA model are presented in Figure 14. The maximum +ve bending moments are 
$34 \mathrm{KN} \cdot \mathrm{m} / \mathrm{m}$ located at level $(5.00 \mathrm{~m})$, and the maximum -ve bending moments $-33 \mathrm{Kn} . \mathrm{m} / \mathrm{m}$ located at level $(7.50 \mathrm{~m})$. The maximum +ve shearing force is $70 \mathrm{KN} / \mathrm{m}$ located at level $(5.00 \mathrm{~m})$, and the maximum -ve shearing force is $-73 \mathrm{KN} / \mathrm{m}$ located at level $(5.00 \mathrm{~m})$, the anchor force no. 1 is $315 \mathrm{KN}$ at level $(10.00 \mathrm{~m})$, the anchor force no. 2 is $105 \mathrm{KN}$ at level $(7.50 \mathrm{~m})$ and the anchor force no. 3 is $427 \mathrm{KN}$ at level $(5.00 \mathrm{~m})$. The max straining actions above is satisfying the stresses for the cross section used AU17 in the Sharm berth.

Table 5 AUI7 geometrical values

\begin{tabular}{lllllll}
\hline & Sectional area & Mass per M & Moment of inertia & Elastic section modulus & Radius of gyration & Coating area* \\
\hline & $\mathrm{cm}^{2}$ & $\mathrm{~kg} / \mathrm{m}$ & $\mathrm{cm}^{4}$ & $\mathrm{~cm}^{3}$ & $\mathrm{~cm}$ & $\mathrm{~m}^{2} / \mathrm{m}$ \\
\hline Per S & 113.4 & 89 & 7270 & 488 & 8.01 & 0.96 \\
Per D & 226.9 & 178.1 & 51400 & 2495 & 15.05 & 1.91 \\
Per T & 340.3 & 267.2 & 70960 & 2855 & 14.44 & 2.86 \\
Per m of wall & 151.2 & 118.7 & 34270 & 1665 & 15.05 & 1.27 \\
\hline
\end{tabular}

Stage No.8 Excav. to elev. 3.00 on PASSIVE side
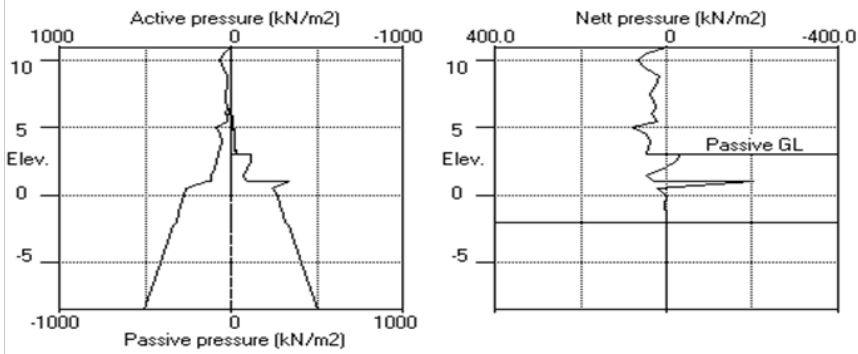

Figure I 3 Active, passive and net pressure for WPC (I I.75 Z section).

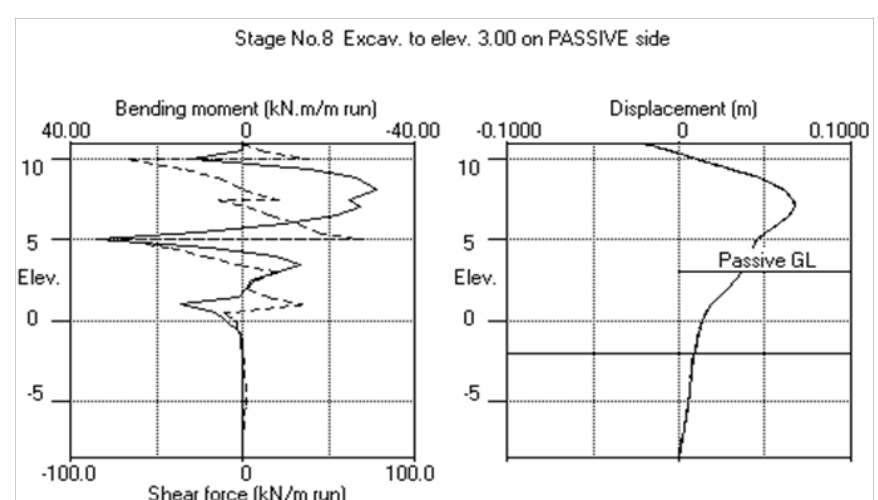

Figure I 4 Total deflection, shearing forces and bending moments for WPC (I I.75 Z section).

\section{Conclusion}

The original objectives for performing a linear FEA analysis outlined in previous Section have been completed. The finite element model verifies the initial design assumptions of Sharm El-shikh berth. This is through the agreement of the maximum deflections between the two models and the maximum stresses. The next step is to use the FEA modeling for design to predict the behavior of this geometry and material (WPC z piles) under various service conditions, which was successfully completed and satisfy all applied loads within the allowable deformation and stresses and it is clearing from this study the governing factor of the PVC design is the deformation wall height not the compressive nor tensile stresses. Therefore, the FEA analysis can be used as a tool for WPC sheet pile $\mathrm{z}$ section design for harbor projects. The total cost for WPC Z section walls is nearly about $40 \%$ of steel sheet pile walls, so we can use it in future marine berths for max. Allowable height $8 \mathrm{~m}$ with three anchors or thrust.

\section{Acknowledgements}

None.

\section{Conflict of interest}

The author declares no conflict of interest.

\section{References}

1. Brandt CW. Load-Duration Behavior of Extruded Wood-Plastic Composites. 2001.

2. Clemons C. Wood-Plastic Composites in the United States: the interfacing of two industries. Forest products journal. 2002;52(6):10-18.

3. Dagher HJ, Lopez-Anido RA, Gardner DJ, et al. Sheet Piling Panels with Elongated Hollows. USP Application. 2004;11:13-301.

4. Dura M, Lopez-Anido, Dagher R, et al. Experimental Behavior of Hybrid Wood-Plastic Composite-FRP Structural Members for Use in Sustained Loading Applications. $8^{\text {th }}$ International Conference on Wood fibre-Plastic Composites. USA; 2005. 189 p.

5. Kahl M, Dagher H, Lopez-Anido, et al. Design of Innovative Hollow Extruded WPC Sheet Piling. $8^{\text {th }}$ International Conference on Wood fiberPlastic Composites. 2005.

6. Prasad P, Mark J, Kandil SH, et al. Science and Technology of Polymers and Advanced Materials Emerging Technologies and Buissness Opportunities. Fourth International Conference on Frontiers of Polymers and Advanced Materials. Cairo, Egypt; 1998. 